\title{
Does weight-for-height and mid upper-arm circumference diagnose the same children as wasted? An analysis using survey data from 2017 to 2019 in Mozambique
}

Tomás Zaba ${ }^{1 *} \mathbb{D}$, Mara Nyawo ${ }^{2}$ and Jose Luis Álvarez Morán ${ }^{3}$

\begin{abstract}
Background: Three different diagnostic criteria are used to identify children aged 6 to 59 months with acute malnutrition: weight-for-height (WHZ), middle upper arm circumference (MUAC) and bilateral pitting oedema. Prevalence of malnutrition from surveys is among the most-used decision support data, however not all diagnostic criteria are used to calculate need, creating a mismatch between programme planning and implementation. With this paper, we investigate if such discrepancies are observed in Mozambique.

Methods: Population-based nutritional anthropometric surveys from 45 districts in Mozambique conducted by the Technical Secretariat for Food Security and Nutrition (SETSAN) and UNICEF between 2017 and 2019 were analysed. We used Cohen's kappa coefficient to measure inter-rater agreement between WHZ and MUAC, Spearman's rankorder coefficient to assess the correlation, binary logistic regression to investigate factors influencing WHZ and MUAC diagnostic classification. We compared acute malnutrition caseload estimates by WHZ, MUAC and oedema to caseloads from combined prevalence estimates.

Results: WHZ and MUAC rarely agree on their diagnostic classification $(K=0.353, \rho<0.001)$ and results did not vary by province. We found positive correlation between WHZ and MUAC (rho $=0.593, \rho<0.0001$ ). Binary logistic regression explained $3.1 \%$ of variation in $\mathrm{WHZ}$ and $12.3 \%$ in the MUAC model. Girls (AOR $=1.6, \rho<0.0001$ ), children $<24$ months ( $A O R=5.3, \rho<0.0001)$ and stunted children ( $A O R=3.5, \rho<0.0001)$ influenced the MUAC classification. In the $\mathrm{WHZ}$ model, children $<24$ months $(\mathrm{AOR}=2.4, \rho<0.0001)$ and stunted children $(\mathrm{AOR}=1.7, \rho<0.0001)$ influenced the classification, sex had no effect. Caseload calculations of global acute malnutrition by WHZ and/ oedema-only and by MUAC and/oedema-only yielded less children than caseload calculations using the combined prevalence estimates. Similarly, caseload calculations for SAM by WHZ and/oedema-only and SAM by MUAC and/ oedema-only yielded less children than the respective combined prevalence calculations.

(Continued on next page)
\end{abstract}

\footnotetext{
*Correspondence: tzaba@unicef.org; tomas.zaba@outlook.com

'United Nations Children's Fund, 1440 Zimbabwe Avenue, Maputo, Mozambique

Full list of author information is available at the end of the article
}

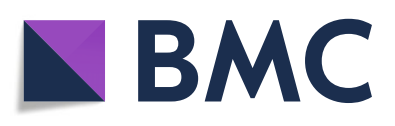

(- The Author(s). 2020 Open Access This article is licensed under a Creative Commons Attribution 4.0 International License, which permits use, sharing, adaptation, distribution and reproduction in any medium or format, as long as you give appropriate credit to the original author(s) and the source, provide a link to the Creative Commons licence, and indicate if changes were made. The images or other third party material in this article are included in the article's Creative Commons licence, unless indicated otherwise in a credit line to the material. If material is not included in the article's Creative Commons licence and your intended use is not permitted by statutory regulation or exceeds the permitted use, you will need to obtain permission directly from the copyright holder. To view a copy of this licence, visit http://creativecommons.org/licenses/by/4.0/ The Creative Commons Public Domain Dedication waiver (http://creativecommons.org/publicdomain/zero/1.0/) applies to the data made available in this article, unless otherwise stated in a credit line to the data. 


\begin{abstract}
(Continued from previous page)
Conclusions: Given the discrepancy in diagnostic classification between WHZ and MUAC in Mozambique, using either one alone for calculating burden underestimates the real number of children in need of treatment and negatively affects nutrition programme planning. We recommend that use of the combined prevalence estimates, based on the three diagnostic criteria of WHZ, MUAC and oedema, be officially adopted. Further analysis is needed to detail the programmatic impact of this change.
\end{abstract}

Keywords: Wasting, WHZ, MUAC, Combined prevalence, Nutrition programme planning, Malnutrition

\section{Background}

Acute malnutrition in children under 5 years is a lifethreatening and devastating disease of epidemic proportions world-wide, and especially in low and middleincome countries [1]. Wasting, or acute malnutrition, is diagnosed using weight-for-height z-scores (WHZ) or mid-upper arm circumference (MUAC) [2]. Its prevalence is estimated through representative populationbased surveys which are carried out at national and/or sub-national level as needed. Based on their findings, response plans are put in place to prevent further deterioration of the nutrition situation [3]. The clinical sign of bilateral pitting oedema is another criteria used to diagnose acute malnutrition [4]. This paper will focus on the two anthropometric indicators.

Practical experience as well as research from different countries has shown that WHZ and MUAC identify different children as being wasted, with a small overlap between the two measurers as described below. These discrepancies have an implication when measuring the prevalence of acute malnutrition and classifying the severity of an area which guides decisions around the need to set up an intervention. This issue was raised during Integrated Phase Classification for Acute Malnutrition (IPC for AMN) workshops in Mozambique, where it was noted that in some areas the prevalence of Global Acute Malnutrition (GAM) by MUAC was higher than GAM by WHZ $[5,6]$.

Evidence from the literature has consistently found that MUAC and WHZ are discrepant. A study conducted by Laillou et al., (2014) in Cambodian children using a secondary data analysis of 11,000 datasets from 2010 and 2012, found that the prevalence of wasting was $3.3 \%$ using MUAC compared to $10.6 \%$ when $\mathrm{WHZ}$ was used [7]. Contrary to this, a study conducted in southern Ethiopia by Tadesse et al., (2017, p.5) found that "MUAC categorized more children as wasted (10.5\%, 95\% CI: 9,6\%- 11,4\%) compared to WHZ (5.4\%, 95\% CI: 4.8\%-6.1\%)" [8].

Still in Cambodia, Wieringa et al., (2018) with the aim of exploring factors associated with wasting by MUAC and by WHZ and using longitudinal data of 4381 children, found that WHZ continued to identify higher rates of wasting than MUAC (14.4 and 10.1\% respectively).
Looking at associations in a multinomial regression model, factors associated with wasting diagnosed by WHZ included being older $(p<0,01)$, being stunted and being male (males were 1.9 times more likely to be wasted); while for MUAC the associated factors were being younger, being female (females were 3.2 times more likely to be wasted) and being stunted (stunted children were 4.9 times more likely to be wasted) and the differences were all statistically significant $(p<0,05)$ [7]. It should be noted that stunting prevalence was $19.7 \%$, which is much lower than stunting prevalence in Mozambique, which is $43 \%$ [9].

A recently published paper by Bilukha and Leidman (2018) analysed 773 population-representative anthropometric surveys from 41 countries that were conducted by Action Contre la Faim (ACF) and the United Nations High Commission for Refugees (UNHCR) between 2001 and 2016. They found that the median prevalence of wasting by WHZ was $10.47 \%$, while by MUAC wasting was 6.66\% (Bilukha and Leidman, 2018 p.1). Mozambique was one of the 41 countries included in the analysis (contributing one survey with 406 children) and the prevalence of wasting by WHZ and MUAC showed the same value of $3.26 \%$ with no confidence interval available. Another study by Grellety \& Golden (2016), analysed data from 47 countries in order to compare the degree and direction of discrepancy between WHZ and MUAC across countries. Again, Mozambique was included, contributing 14 surveys with an overall 3828 children aged 6 to 59 months. Results for Mozambique showed that of the total cases of acute malnutrition (579), $21 \%$ where identified by $\mathrm{WHZ}<-2$ while over $43.9 \%$ were identified by MUAC $<125 \mathrm{~mm}$ [8].

In Mozambique, although most surveys collect MUAC as well as weight and height measurements, acute malnutrition prevalence estimates use WHZ and/or oedema only. The Mozambique National Protocol for treatment of children with acute malnutrition follows WHO recommendations whereby programme admissions are made using either WHZ or MUAC classifications, as well as oedema [9-11]. However, for programme planning, estimates of the number of children in need of treatment are calculated using prevalence obtained by WHZ only. Despite a well-documented recognition that children with a low MUAC have an increased risk of 
death [12], WHZ has traditionally been preferred over MUAC when estimating prevalence, and MUAC-based prevalence estimates have only been used in the absence of WHZ. This situation has changed somewhat with the recent updates made in the new IPC Acute Malnutrition Version 3 guidelines. MUAC-based prevalence can now be used to classify severity even when WHZ-based prevalence estimates also exist, as long as there is historical data showing the relationship between MUAC and WHZ in the context under analysis [13].

The objective of the present study is to understand the following research questions: Is there any agreement between WHZ and MUAC in Mozambique when identifying wasting? How do WHZ and MUAC correlate in Mozambique and what are the possible factors that explain discrepancies? How does use of the combined estimates change the prevalence and burden estimates in Mozambique? How different is the combined prevalence using WHZ and MUAC and/oedema from either WHZ and/oedema-only or MUAC and/oedema-only prevalence? Considering that these questions have not previously been analysed in Mozambique, we believe that analysing existing data to answer these questions will improve programme planning and implementation of the national protocol for treatment of acute malnutrition.

\section{Methods}

\section{Source of data}

The study used 46 district level surveys that were implemented in 45 different districts (one district had 2 surveys, of total 161 districts in Mozambique) between 2017 and 2019. Almost all of the 11 Provinces of Mozambique were represented in the study sample, except for Niassa and Maputo Cidade. All surveys were population-based, and designed to be representative at district level following the SMART methodology [14]. The surveys were conducted in order to assess the need for emergency nutrition programmes and were led by the Government through the Technical Secretariat for Food Security and Nutrition (SETSAN) and Partners. All surveys used a two-stage cluster sampling approach with probability proportional to size of the population applied in stage 1, following the SMART methodology. Anthropometric measurements were taken using the same instruments across all surveys and enumerators were trained and submitted to a standardization test. A calendar of local events was used in all surveys to estimate age in months for children without official document to extract birthdate.

\section{Data processing}

Data was initially cleaned using ENA for SMART software version July 9th, 2015 [14] and Z-scores were calculated according to the WHO 2006 growth reference.
SMART flags ( $\pm 3 \mathrm{z}$-scores) were used to exclude non plausible WHZ data and overall quality of data was verified through the SMART plausibility check in ENA to ensure that all data used met documented quality standards [14]. There were no exclusion criteria for MUAC. Datasets were then imported to IBM SPSS version 25 (IBM Corp. Released, 2016) where further analysis was carried out. Wasting by WHZ was defined as $<-2$ Zscores and wasting by MUAC as $<125 \mathrm{~mm}$.

The first objective of the analysis was to ascertain if WHZ and MUAC classified the same children as wasted. Being a binary test, which can return only two possible values, Cohen's Kappa $(\mathrm{k})$ coefficient was used to measure the inter-rater agreement between diagnosis of wasting by WHZ and by MUAC [15-17] and results were split by province. The second objective was to see how the two indicators (WHZ and MUAC) correlated. Since MUAC distribution was not normal as per the Kolmogorov-Smirov test of normality $(\mathrm{D}=0.0225, p<$ 0.0001 ), a Spearman's rank-order correlation was run $[18,19]$. The third objective was to identify what factors are associated with the observed discrepancy between WHZ and MUAC and to calculate the corresponding odds ratios. To do so, a binary logistic regression applying the enter method was used [20,21] with first wasting by WHZ as the dichotomous dependent variable, and sex (boys as reference), age in two categories ( $\geq 24$ months as reference), and presence of stunting ("no" as reference) as independent variables; secondly, wasting by WHZ was replaced with wasting by MUAC as the dependent variable and the independent variables remained the same. For the analysis of difference between WHZ and MUAC bilateral pitting oedema was excluded.

For the analysis of combined prevalence, bilateral pitting oedema was included, and was then called Global Acute Malnutrition (GAM). GAM is clinically divided into severe acute malnutrition (SAM) and moderate acute malnutrition (MAM) [2]. Combined GAM (cGAM) included children with $\mathrm{WHZ}<-2$ and/or MUAC $<125$ and/or presence of bilateral pitting oedema, and combined prevalence of SAM (cSAM) included children with $\mathrm{WHZ}<-3$ and/or MUAC $<115$ and/or presence of bilateral pitting oedema. Caseload was then calculated by applying the formula as described in Fig. 1 and using an incidence correction factor of 2.6 [22].

\section{Results}

There were 12,639 children aged between 6 and 59 months included in our analysis, from the 46 surveys in 45 districts distributed across 9 (of 11) provinces in Mozambique. Mean age was $30.4 \pm 14.8$ months, $37.9 \%$ of the children were less than 24 months and $50.2 \%$ were girls. Mean MUAC was $149 \mathrm{~mm} \pm 13 \mathrm{~mm}$ with ranges between $93 \mathrm{~mm}$ and $211 \mathrm{~mm}$. MUAC flags were not 
- Formula for combined prevalence of GAM (cGAM)

$c G A M=((W H Z<-2)|(M U A C<125)|(E D E M A=1))$

- Formula for combined prevalence of SAM (cSAM)

$c S A M=((W H Z<-3)|(M U A C<115)|(E D E M A=1))$

where:

Edema $=1$ : refers to a condition of presence of bilateral oedema.

- Formula for caseload

Caseload $=N \times P \times K$

where:

$\mathrm{N}$ : corresponds to the size of population of children 6 to 59 months old of the target area.

$\mathrm{P}$ : estimated prevalence of global acute malnutrition or SAM in this analysis.

$\mathrm{K}$ : incidence correction factor.

Fig. 1 Description of the formulas used for calculating the combined prevalence and caseload

used. Mean WHZ was $-0.0045 \pm 1.03$ with ranges between - 3.589 z-scores and $3.310 \mathrm{z}$-scores. Flags for extreme values for WHZ were removed.

Overall, prevalence of wasting by MUAC was higher than WHZ in the majority of districts (58.7\%). It was interesting to observe that unlike other provinces included in this analysis, in Zambézia wasting by MUAC was higher in 8 of the 9 districts included in the study and in Cabo Delgado wasting by MUAC was higher in 4 of the 5 districts included in the study. Further details are presented below in Table 1.

\section{Level of agreement between WHZ and MUAC in diagnosing wasting}

Results from the Cohen's $\mathrm{k}$ test show a minimal agreement between the two diagnostic tests, $\mathrm{k}=0.353, \rho=$ 0.000 , meaning that overall between 4 to $15 \%$ of data points for each child agree on the diagnosis of wasting by WHZ and by MUAC (Fig. 2). At provincial level the same pattern was observed with some highlights in Sofala and Inhambane provinces where a very low level of agreement was observed, and only $0-4 \%$ of data agreed on the diagnosis of wasting by WHZ and by MUAC. A weak level of agreement was observed in Maputo province, corresponding to 15-35\% agreement (Table 2). Figure 2 illustrates the larger number of children identified as wasted using MUAC and shows the level of overlap between the two diagnostic criteria.

\section{Correlation between WHZ and MUAC}

There was a positive correlation between MUAC scores and WHZ scores, which was statistically significant (rho $=0.593, \rho<0.0001$ ). As MUAC score increases, so does WHZ score and vice-versa, suggesting that the observed discrepancies could be explained by other factors (Fig. 3).

Factors associated with wasting by $\mathrm{WHZ}$ and wasting by MUAC

Two binary logistic regression tests were performed to ascertain the effects of age, sex and stunting on the diagnosis of wasting using WHZ and using MUAC. The two tables below show the results of the regression model for wasting by WHZ (Table 3) and the regression model for wasting by MUAC (Table 4). Overall, the model presented in Table 3 was able to explain only $3.1 \%$ of the variation in WHZ diagnosis and the model was statistically significant $\left(X^{2}=94.071, \rho<0.0001\right)$, while the model presented in Table 4 explained $12.3 \%$ of the variation in MUAC diagnosis, and was also statistically significant $\left(X^{2}=430.429, \rho<0.0001\right)$. This means that there are many other factors that contribute to the variation seen, in addition to the factors included in each model.

Age and stunting were the variables with a statistically significant difference $(\rho<0.001)$ in the model by WHZ. The model predicted that younger children (less than 24 months) were 2.4 times more likely to be diagnosed as wasted using WHZ than older children. Stunted 
Table 1 Prevalence of wasting by WHZ only and by MUAC only in 45 districts surveyed between 2017 and 2019 in Mozambique

\begin{tabular}{|c|c|c|c|c|}
\hline Province & District & Number of children & Prevalence of wasting by $\mathrm{WHZ}, 95 \% \mathrm{Cl}$ & Prevalence of wasting by MUAC, $95 \% \mathrm{Cl}$ \\
\hline \multirow[t]{5}{*}{ Cabo Delgado } & Balama & 237 & $3.4 \%(1.06-5.7)$ & 7.6\%, (4.2-10.9) \\
\hline & Ibo & 256 & $10.9 \%(7.1-14.8)$ & $7 \%,(3.8-10.1)$ \\
\hline & Mecufi & 323 & $4.6 \%(2.3-7.0)$ & $8.7 \%,(5.6-11.8)$ \\
\hline & Meluco & 259 & $3.5 \%(1.2-5.7)$ & $4.2 \%,(1.7-6.7)$ \\
\hline & Namuno & 363 & $5.2 \%(2.9-7.5)$ & $6.9 \%,(4.3-9.5)$ \\
\hline \multirow[t]{4}{*}{ Nampula } & Mogovolas & 378 & $4.2 \%(2.2-6.3)$ & $4 \%,(2.0-6.0)$ \\
\hline & Monapo & 353 & $2 \%(0.9-4.2)$ & $5.9 \%,(3.5-8.4)$ \\
\hline & Nacala-a-Velha & 270 & $7 \%(4.0-12.4)$ & $7.8 \%,(4.6-10.9)$ \\
\hline & Ribaue & 380 & $2.6 \%(1.4-5.1)$ & $2.1 \%,(0.6-3.6)$ \\
\hline \multirow[t]{9}{*}{ Zambézia } & Maganja da Costa & 197 & $2 \%(0.7-5.5)$ & $5.1 \%,(2.0-8.2)$ \\
\hline & Milange & 338 & $3.8 \%(1.8-5.9)$ & $6.5 \%,(3.9-9.2)$ \\
\hline & Morrumbala & 354 & $4.5 \%(3.5-6.7)$ & $6.8 \%,(4.1-9.4)$ \\
\hline & Namacurra & 207 & $2.9 \%(1.2-7.0)$ & $3.9 \%,(1.2-6.5)$ \\
\hline & Nicoadala & 262 & $0.8 \%(0.2-3.0)$ & $5.7 \%,(2.8-8.5)$ \\
\hline & Gurue & 336 & $2.4 \%(1.1-5.3)$ & $4.5 \%,(2.2-6.7)$ \\
\hline & Lugela & 321 & $4 \%(2.4-7.0)$ & $5.3 \%,(2.8-7.6)$ \\
\hline & Molumbo & 288 & $4.2 \%(2.4-7.3)$ & $4.9 \%,(2.3-7.3)$ \\
\hline & Pebane & 407 & $4.2 \%(2.5-7.0)$ & $4.2 \%,(2.3-6.1)$ \\
\hline \multirow[t]{8}{*}{ Tete } & Cahora-Bassa & 341 & $2.6 \%(0.9-4.4)$ & $1.8 \%,(0.4-3.2)$ \\
\hline & Changara & 235 & $2.1 \%(0.2-4.0)$ & $2.1 \%,(0.2-4.0)$ \\
\hline & Doa & 222 & $5.4 \%(2.4-8.5)$ & $9 \%,(5.2-12.8)$ \\
\hline & Moatize & 198 & $1 \%(-0.4-2.4)$ & $2.5 \%,(0.3-4.7)$ \\
\hline & Mutarara (in 2019) & 214 & $3.7 \%(1.2-6.3)$ & $4.7 \%,(1.8-7.5)$ \\
\hline & Mutarara (in 2018) & 395 & $2.3 \%(0.8-3.4)$ & $3 \%,(1.3-4.7)$ \\
\hline & Chiuta & 218 & $5 \%(2.1-8.0)$ & $1.8 \%,(0.04-3.6)$ \\
\hline & Magoe & 212 & $4.2 \%,(1.5-7.0)$ & $1.9 \%,(0.04-3.7)$ \\
\hline \multirow[t]{5}{*}{ Sofala } & Beira & 224 & $4.5 \%,(2.3-8.7)$ & $2.7 \%,(0.5-4.8)$ \\
\hline & Buzi & 187 & $1.6 \%,(0.6-4.6)$ & $2.7 \%,(0.3-5.0)$ \\
\hline & Caia & 230 & $3.5 \%(1.6-8.0)$ & $2.2 \%,(0.3-4.1)$ \\
\hline & Dondo & 178 & $4.5 \%,(2.1-10.1)$ & $1.1 \%,(-0.4-2.7)$ \\
\hline & Nhamatanda & 205 & $2.9 \%,(1.3-7.0)$ & $1 \%,(-0.4-2.3)$ \\
\hline \multirow[t]{4}{*}{ Manica } & Gondola & 297 & $2.7 \%,(0.8-4.5)$ & $1.3 \%,(0.03-2.7)$ \\
\hline & Macossa & 237 & $2.5 \%,(0.5-4.5)$ & $5.1 \%,(2.3-7.9)$ \\
\hline & Sussundenga & 186 & $1.6 \%,(-0.2-3.4)$ & $1.6 \%,(-0.2-3.4)$ \\
\hline & Tambara & 197 & $2 \%,(0.04-4.0)$ & $6.1 \%,(2.7-9.5)$ \\
\hline \multirow[t]{3}{*}{ Inhambane } & Funhalouro & 245 & $1.2 \%,(-0.16-2.6)$ & $0.4 \%,(-0.4-1.2)$ \\
\hline & Govuro & 281 & $1.1 \%,(-0.14-2.3)$ & $1.4 \%,(0.03-2.8)$ \\
\hline & Panda & 253 & $0 \%,(0.0-0.0)$ & $1.6 \%,(0.03-3.1)$ \\
\hline \multirow[t]{5}{*}{ Gaza } & Chibuto & 277 & $1.8 \%,(0.2-3.4)$ & $0.4 \%,(-0.4-1.1)$ \\
\hline & Chicualacuala & 273 & $0.4 \%,(-0.4-1.1)$ & $1.5 \%,(0.03-2.9)$ \\
\hline & Chigubo & 282 & $1.1 \%,(-0.1-2.3)$ & $1.4 \%,(0.03-2.8)$ \\
\hline & Guija & 279 & $1.4 \%,(0.03-2.8)$ & $1.8 \%,(0.2-3.4)$ \\
\hline & Mabalane & 374 & $0.3 \%,(-0.3-0.8)$ & $0.8 \%,(-0.1-1.7)$ \\
\hline Maputo Provincie & Magude & 265 & $1.5 \%,(0.03-2.9)$ & $1.1 \%,(-0.1-2.4)$ \\
\hline
\end{tabular}


Table 1 Prevalence of wasting by WHZ only and by MUAC only in 45 districts surveyed between 2017 and 2019 in Mozambique (Continued)

\begin{tabular}{|c|c|c|c|c|}
\hline Province & District & Number of children & Prevalence of wasting by $\mathrm{WHZ}, 95 \% \mathrm{Cl}$ & Prevalence of wasting by MUAC, $95 \% \mathrm{Cl}$ \\
\hline & Manhica & 266 & $4.1 \%,(1.7-6.5)$ & $3 \%,(0.9-5.1)$ \\
\hline & Namaacha & 339 & $2.7 \%,(0.9-4.4)$ & $2.1 \%,(0.5-3.6)$ \\
\hline TOTAL & & 12,639 & & \\
\hline
\end{tabular}

children were 1.7 times more likely to be diagnosed as wasted using WHZ than non-stunted children. Being either a boy or a girl had no effect on the diagnosis of wasting by WHZ. Breakdown analysis by province showed an increased likelihood to be diagnosed positive for wasting using WHZ in Cabo Delgado (3.1 times more likely), Zambézia (2.7 times more likely), Tete (1.9 times more likely) and Sofala (2.9 times more likely).

Table 4 shows results of the regression model for wasting by MUAC. As per this model, MUAC-based diagnosis is significantly influenced by all three factors considered with increased odds ratios for sex, age and stunting $(\rho<0.001)$. Girls were 1.6 times more likely to be diagnosed as wasted when using MUAC, children aged less than 24 months were 5.3 times more likely to be wasted than older children, and stunted children are 3.5 times more likely to be wasted than non-stunted children. Breakdown analysis by province is presented below in Table 4.

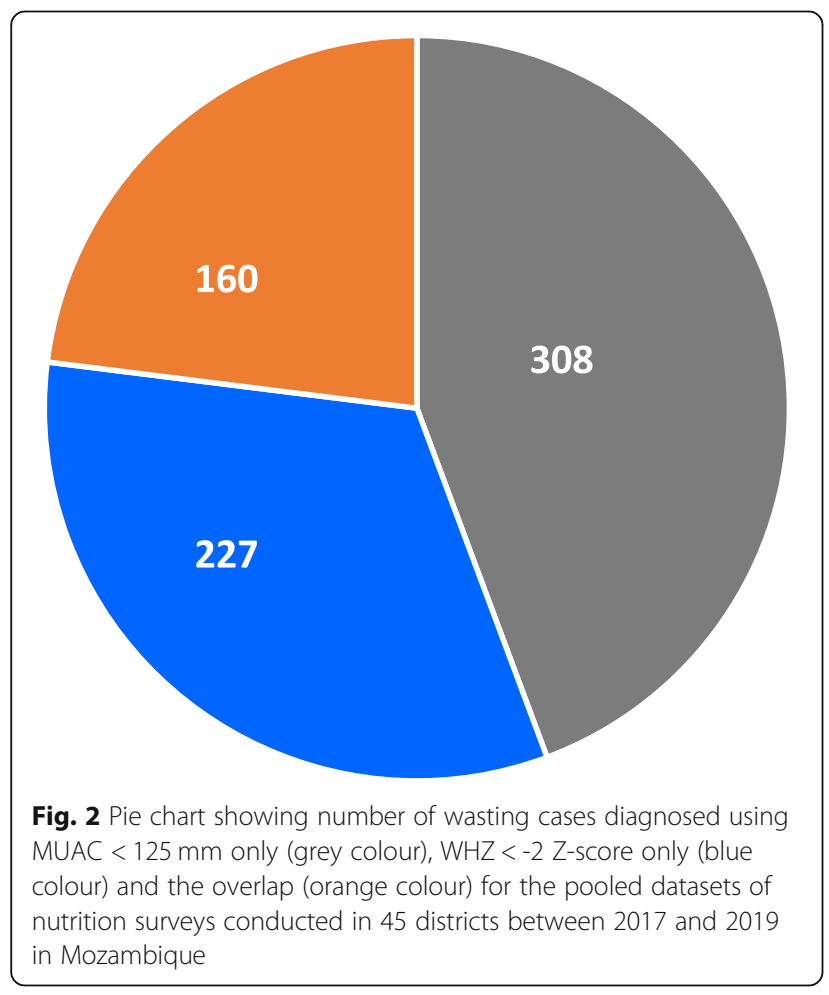

Programmatic implications of the difference between WHZ-only prevalence and MUAC-only prevalence

These findings clearly highlight the fact that WHZ and MUAC diagnose different children as wasted and that they rarely agree, meaning that they rarely identify the same children. From a programmatic point of view, this difference results in many children who are not included in programme planning - including for advocacy, supply planning, human resource and financial needs - when WHZ-only or MUAC-only diagnostic criteria are used. As a result, the Nutrition Sector combines both WHZ and MUAC estimates (as proposed by Grellety \& Golden, 2016) to ensure that all children who are acutely malnourished and in need of life-saving treatment are considered when planning programme responses and estimating numbers in need.

\section{Combined prevalence of global acute malnutrition}

Since there were not many cases of bilateral pitting oedema observed, GAM by WHZ and GAM by MUAC presented in Fig. 4 follows the same distribution as reported in Table 1. Looking at cGAM, prevalence ranges from 0.80 to $14.84 \%$. The same pattern was observed for SAM, where SAM by MUAC and/or oedema diagnosed

Table 2 Results of the Cohen's Kappa test for the pooled datasets grouped by Province from nutrition surveys conducted from 2017 to 2019 in Mozambique

\begin{tabular}{llll}
\hline & Value of Kappa & Level of agreement ${ }^{\mathrm{a}, \mathrm{b}}$ & $\rho$-value \\
\hline Pooled dataset & 0.353 & Minimal & $<0.001$ \\
Results split by province & & \\
Cabo Delgado & 0.363 & Minimal & $<0.001$ \\
Nampula & 0.385 & Minimal & $<0.001$ \\
Zambézia & 0.387 & Minimal & $<0.001$ \\
Tete & 0.377 & Minimal & $<0.001$ \\
Sofala & 0.086 & None & 0.004 \\
Manica & 0.288 & Minimal & $<0.001$ \\
Inhambane & 0.125 & None & $<0.001$ \\
Gaza & 0.25 & Minimal & $<0.001$ \\
Maputo province & 0.464 & Weak & $<0.001$
\end{tabular}

a Level of agreement taken from McHugh (2012)

bLevel of agreement according to value of Kappa: None: 0-0.20; Minimal: 0.210.39; Weak: 0.40-0.59; Moderate: 0.60-0.79; Strong: 0.80-0.90; Almost perfect: above 0.90 . 


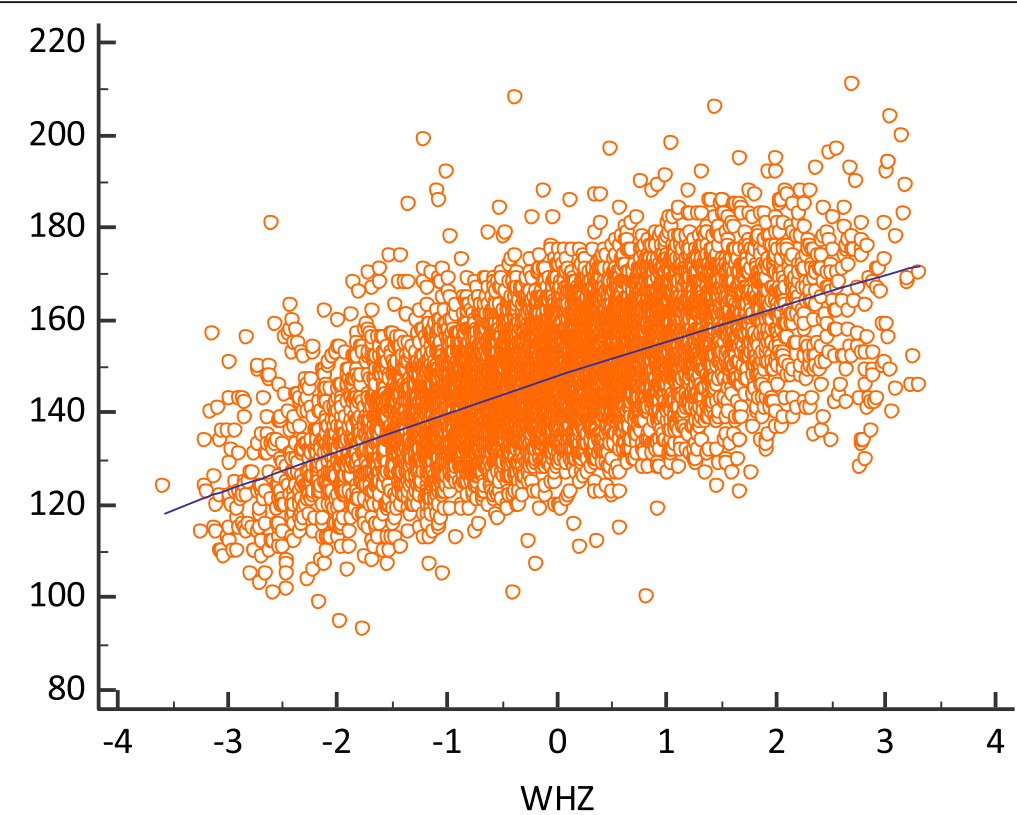

Fig. 3 Scatter diagram of Spearman rank correlation with MUAC scores on Y axis and WHZ scores on X axis, from the pooled datasets of nutrition surveys conducted in 45 districts from 2017 to 2019 in Mozambique. Each orange dot corresponds to a point where MUAC scores and WHZ scores are linked. The blue line is the linear fit

more children than SAM by WHZ and/or oedema (Fig. 5) and for the combined prevalence (cSAM).

\section{Number of children in need of treatment using CGAM and cSAM}

The caseload calculation for a 12-month scenario considering an incidence correction factor of 2.6 shows some discrepancies when using cGAM, GAM by WHZonly and GAM by MUAC-only as expected. Using cGAM gave an estimated 224,000 children expected to suffer from acute malnutrition during 1 year, while using GAM by WHZ and/oedema-only yielded 127,000 children corresponding to $43.3 \%$ less (Fig. 6). Using GAM by MUAC and/or oedema-only yielded 152,000 children, corresponding to $32.1 \%$ less than cGAM estimates. For SAM, the combined estimates (cSAM) yielded 95,000 children in need of treatment (Fig. 7), while using SAM by WHZ and/oedema-only yielded 24,000 (74.7\% less) and SAM by MUAC and/oedema 87,000 children (8.4\% less).

\section{Discussion}

Our analysis sought to investigate whether there are discrepancies between WHZ and MUAC diagnostic criteria, to explore what may explain the discrepancies and what the potential implications may be for nutrition programme planning and design in Mozambique. We used a large sample from pooled surveys with representation of nine out of the eleven provinces in Mozambique.
Our study findings show that in Mozambique WHZ and MUAC classifications of wasting very rarely agree as assessed by Kohen's test (Table 2). This is observed in all the provinces included in this analysis. These results are not surprising because they corroborate field level observations as well as results reported from studies in other countries. Studies across Africa and other regions have shown similar levels of discordance, showing WHZ diagnosing more children than MUAC [23] in some locations, while in other locations MUAC diagnoses more children than WHZ $[8,24]$. Our analysis shows that in the case of Mozambique, MUAC diagnoses more children than WHZ (Fig. 2). Our findings are different to those reported by Bilukha \& Leidman (2018) which showed no difference between WHZ and MUAC for Mozambique. A reason for this could be that our analysis comprises many more data points $(12,639$ compared to Bilukha and Leidman's 406), and greater geographical representation across the country.

With regards to the correlation between WHZ and MUAC, our study findings show that when values for WHZ increase, so do values for MUAC, and vice-versa as per the Spearman's correlation (rho) (Fig. 3). This suggests existence of other factors, in addition to those tested in this study, influencing the observed diagnostic discrepancy. Our findings are not distant from others. Bilukha \& Leidman (2018), with data from almost all continents, found a positive correlation between WHZ and MUAC (above 0.5). The correlation coefficient was lowest (rho $=0.3553$ ) in Eastern and Southern Africa. 
Table 3 Binary logistic regression model for wasting by WHZ. Results are presented as the overall of the 45 districts and breakdown by province, using the pooled dataset of nutrition surveys collected between 2017 and 2019 in Mozambique

\begin{tabular}{|c|c|c|c|c|c|c|}
\hline \multirow[t]{2}{*}{ Step 1} & & \multirow[t]{2}{*}{ B } & \multirow[t]{2}{*}{ Sig. } & \multirow[t]{2}{*}{$\operatorname{Exp}(B)$} & \multicolumn{2}{|c|}{ 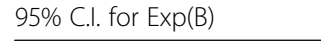 } \\
\hline & & & & & Lower & Upper \\
\hline \multirow[t]{3}{*}{ Overall } & Sex (girls) & -0.168 & 0.108 & 0.846 & 0.689 & 1.037 \\
\hline & Age (<24 months) & 0.865 & 0.000 & 2.375 & 1.934 & 2.918 \\
\hline & Stunting (yes) & 0.523 & 0.000 & 1.686 & 1.375 & 2.068 \\
\hline \multirow[t]{3}{*}{ Cabo Delgado } & Sex (girls) & 0.087 & 0.711 & 1.091 & 0.688 & 1.73 \\
\hline & Age (<24 months) & 1.132 & 0.000 & 3.102 & 1.935 & 4.972 \\
\hline & Stunting (yes) & 0.251 & 0.286 & 1.285 & 0.811 & 2.038 \\
\hline \multirow[t]{3}{*}{ Nampula } & Sex (girls) & 0.124 & 0.663 & 1.132 & 0.647 & 1.981 \\
\hline & Age (<24 months) & 0.549 & 0.054 & 1.731 & 0.99 & 3.027 \\
\hline & Stunting (yes) & 0.341 & 0.237 & 1.407 & 0.799 & 2.476 \\
\hline \multirow[t]{3}{*}{ Zambézia } & Sex (girls) & -0.511 & 0.022 & 0.6 & 0.388 & 0.928 \\
\hline & Age (<24 months) & 0.992 & 0.000 & 2.696 & 1.74 & 4.176 \\
\hline & Stunting (yes) & 0.374 & 0.084 & 1.453 & 0.951 & 2.219 \\
\hline \multirow[t]{3}{*}{ Tete } & Sex (girls) & 0.074 & 0.77 & 1.077 & 0.655 & 1.772 \\
\hline & Age (<24 months) & 0.629 & 0.013 & 1.875 & 1.14 & 3.084 \\
\hline & Stunting (yes) & 1.041 & 0.000 & 2.832 & 1.688 & 4.754 \\
\hline \multirow[t]{3}{*}{ Sofala } & Sex (girls) & -0.946 & 0.013 & 0.388 & 0.184 & 0.82 \\
\hline & Age (<24 months) & 1.053 & 0.003 & 2.866 & 1.422 & 5.776 \\
\hline & Stunting (yes) & 0.194 & 0.598 & 1.214 & 0.591 & 2.492 \\
\hline \multirow[t]{3}{*}{ Manica } & Sex (girls) & -0.938 & 0.056 & 0.392 & 0.15 & 1.022 \\
\hline & Age (<24 months) & 0.771 & 0.084 & 2.161 & 0.903 & 5.172 \\
\hline & Stunting (yes) & 0.326 & 0.469 & 1.386 & 0.573 & 3.35 \\
\hline \multirow[t]{3}{*}{ Inhambane } & Sex (girls) & 16.948 & 0.993 & $>>100^{a}$ & n. $a^{b}$ & n.a $a^{b}$ \\
\hline & Age (<24 months) & 1.248 & 0.153 & 3.483 & 0.629 & 19.279 \\
\hline & Stunting (yes) & -0.485 & 0.661 & 0.615 & 0.071 & 5.368 \\
\hline \multirow[t]{3}{*}{ Gaza } & Sex (girls) & 0.211 & 0.698 & 1.235 & 0.426 & 3.584 \\
\hline & Age (<24 months) & 0.723 & 0.183 & 2.061 & 0.71 & 5.983 \\
\hline & Stunting (yes) & -1.263 & 0.225 & 0.283 & 0.037 & 2.176 \\
\hline \multirow[t]{3}{*}{ Maputo province } & Sex (girls) & -0.213 & 0.613 & 0.808 & 0.354 & 1.845 \\
\hline & Age (<24 months) & 0.508 & 0.223 & 1.662 & 0.735 & 3.761 \\
\hline & Stunting (yes) & 0.49 & 0.309 & 1.632 & 0.635 & 4.198 \\
\hline
\end{tabular}

${ }^{\mathrm{a}}$ This province had only 6 cases of wasting and all of them were girls. ${ }^{\mathrm{b}}$ not applicable

When looking at factors that may explain the discrepancy between WHZ and MUAC diagnosis our binary logistic regression, using the same explanatory variables, was able to explain $3.1 \%$ of the variation in $\mathrm{WHZ}$ and $12.3 \%$ of the variation in MUAC with both models fitting significantly well $\left(\mathrm{X}^{2}=94.071, \rho<0.0001\right.$ for WHZ and $\mathrm{X}^{2}=430.429, \rho<0.0001$ for MUAC). Consistent with evidence in the literature, in our models stunted children have a significantly increased likelihood of being diagnosed as wasted by MUAC (AOR $=3.5, \rho<$ 0.0001 ), younger children (less than 24 months) have a higher likelihood of being diagnosed as wasted by
MUAC $(\mathrm{AOR}=5.3, \rho<0.0001)$ and females also have an increased likelihood of wasting $(\mathrm{AOR}=1.6, \rho<0.0001)$ [25]. Our findings of gender were different from Bilukha \& Leidman's (2018) results which found that the "proportion of females in the sample was not significantly associated with prevalence of wasting by MUAC". In our study the significance of association between these three factors did not change by province, and further increased the AOR (Table 3 for WHZ and Table 4 for MUAC), especially in Cabo Delgado (3.1 times more likely), Zambezia (2.7 times more likely), Tete (1.9 times more likely) and Sofala (2.9 times more likely). Our 
Table 4 Binary logistic regression model for wasting by MUAC. Results are presented as the overall of the 45 districts and breakdown by province using the pooled dataset of nutrition surveys collected between 2017 and 2019 in Mozambique

\begin{tabular}{|c|c|c|c|c|c|c|}
\hline \multirow[t]{2}{*}{ Step 1} & & \multirow[t]{2}{*}{ B } & \multirow[t]{2}{*}{ Sig. } & \multirow[t]{2}{*}{$\operatorname{Exp}(B)$} & \multicolumn{2}{|c|}{ 95\% C.I. for $\operatorname{Exp}(B)$} \\
\hline & & & & & Lower & Upper \\
\hline \multirow[t]{3}{*}{ Overall } & Sex (girls) & 0.473 & 0.000 & 1.605 & 1.325 & 1.945 \\
\hline & Age (<24 months) & 1.668 & 0.000 & 5.304 & 4.297 & 6.547 \\
\hline & Stunting (yes) & 1.244 & 0.000 & 3.47 & 2.852 & 4.221 \\
\hline \multirow[t]{3}{*}{ Cabo Delgado } & Sex (girls) & 0.809 & 0.000 & 2.247 & 1.433 & 3.522 \\
\hline & Age (<24 months) & 2.062 & 0.000 & 7.864 & 4.779 & 12.939 \\
\hline & Stunting (yes) & 1.211 & 0.000 & 3.357 & 2.113 & 5.333 \\
\hline \multirow[t]{3}{*}{ Nampula } & Sex (girls) & 0.519 & 0.049 & 1.68 & 1.002 & 2.818 \\
\hline & Age (<24 months) & 1.48 & 0.000 & 4.393 & 2.527 & 7.638 \\
\hline & Stunting (yes) & 0.843 & 0.002 & 2.323 & 1.359 & 3.972 \\
\hline \multirow[t]{3}{*}{ Zambézia } & Sex (girls) & 0.15 & 0.394 & 1.162 & 0.822 & 1.643 \\
\hline & Age (<24 months) & 1.739 & 0.000 & 5.693 & 3.808 & 8.511 \\
\hline & Stunting (yes) & 0.758 & 0.000 & 2.135 & 1.504 & 3.031 \\
\hline \multirow[t]{3}{*}{ Tete } & Sex (girls) & 0.621 & 0.019 & 1.86 & 1.108 & 3.122 \\
\hline & Age (<24 months) & 1.576 & 0.000 & 4.837 & 2.799 & 8.36 \\
\hline & Stunting (yes) & 1.653 & 0.000 & 5.224 & 2.935 & 9.298 \\
\hline \multirow[t]{3}{*}{ Sofala } & Sex (girls) & 0.772 & 0.109 & 2.164 & 0.842 & 5.563 \\
\hline & Age (<24 months) & 1.283 & 0.008 & 3.607 & 1.407 & 9.251 \\
\hline & Stunting (yes) & 1.859 & 0.000 & 6.419 & 2.416 & 17.057 \\
\hline \multirow[t]{3}{*}{ Manica } & Sex (girls) & 0.69 & 0.076 & 1.993 & 0.931 & 4.267 \\
\hline & Age (<24 months) & 1.665 & 0.000 & 5.286 & 2.388 & 11.699 \\
\hline & Stunting (yes) & 1 & 0.012 & 2.718 & 1.247 & 5.921 \\
\hline \multirow[t]{3}{*}{ Inhambane } & Sex (girls) & 0.116 & 0.866 & 1.123 & 0.294 & 4.293 \\
\hline & Age (<24 months) & 0.786 & 0.25 & 2.195 & 0.575 & 8.382 \\
\hline & Stunting (yes) & 2.496 & 0.002 & 12.139 & 2.493 & 59.095 \\
\hline \multirow[t]{3}{*}{ Gaza } & Sex (girls) & 1.542 & 0.016 & 4.675 & 1.332 & 16.414 \\
\hline & Age (<24 months) & 1.427 & 0.008 & 4.165 & 1.447 & 11.992 \\
\hline & Stunting (yes) & 0.843 & 0.104 & 2.324 & 0.84 & 6.43 \\
\hline \multirow[t]{3}{*}{ Maputo province } & Sex (girls) & -0.472 & 0.357 & 0.624 & 0.228 & 1.705 \\
\hline & Age (<24 months) & 1.153 & 0.02 & 3.168 & 1.203 & 8.341 \\
\hline & Stunting (yes) & 1.393 & 0.004 & 4.027 & 1.541 & 10.525 \\
\hline
\end{tabular}

analysis cannot explain these variations in our results between provinces, and we suggest more research is important to better understand variations.

Although evidence on body composition in paediatrics is very rare given that it is a period of rapid growth and physical development $[26,27]$, available evidence suggests that the influence of stunting and its respective increased likelihood may be related to body composition, specifically muscle mass that is mainly located in the limbs and "the muscle arm area or circumference can be considered as a proxy estimate of muscle mass" and "muscle mass indices derived from mid-upper-arm-circumference are related to height-for-age" $[27,28]$. A study by Myatt et al. (2009) also highlighted difference in body shape [body composition] using cross-sectional data of Ethiopian children, grouped by settled agrarian or semi-nomadic pastoralist, found that WHZ and MUAC observed similar prevalence estimates in agrarian children, but different estimates in pastoralist children with WHZ returning a significantly higher prevalence estimate compared to MUAC [29]. In summary, there is no single reason that explains the discrepancies found between WHZ and MUAC, which this analysis corroborates. This highlights the need to measure both indices at surveys and to use both figures for planning, as which is higher or lower varies from place to place and is very 

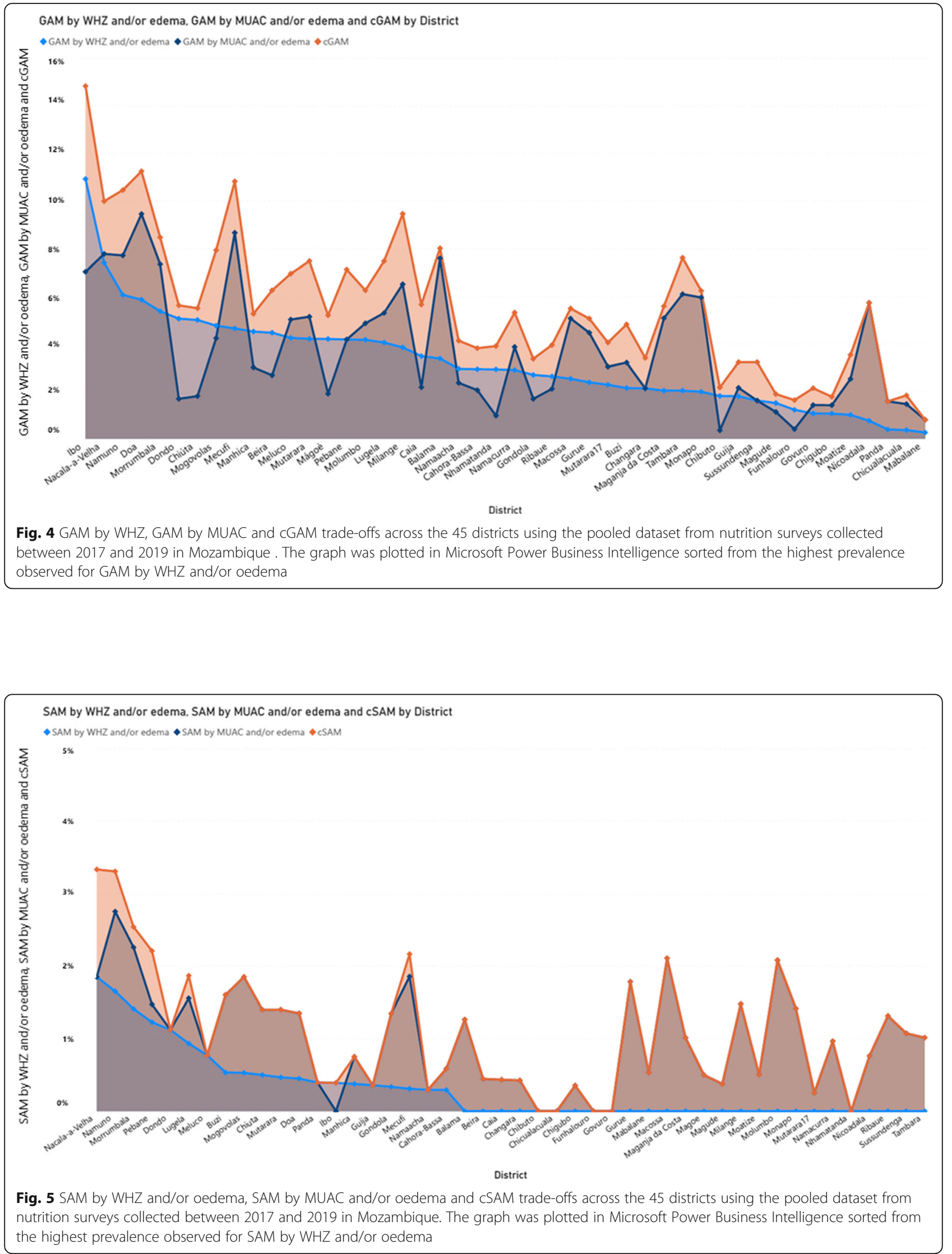
Caseload GAMbyWHZ and/or edema - Caseload GAMbyMUAC and/or edema Caseload cGAM

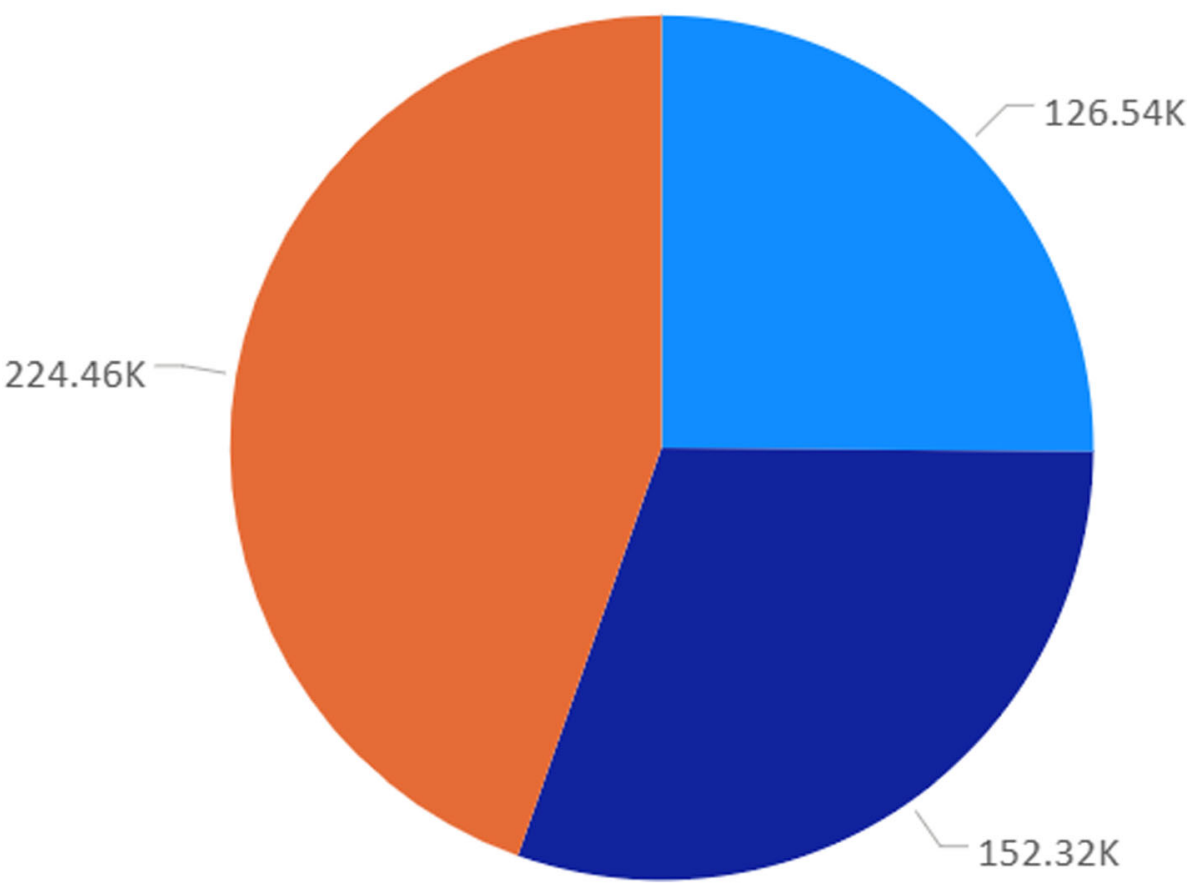

Fig. 6 Total number of children (in thousands) in need of treatment using GAM by WHZ only, GAM by MUAC only and cGAM (combined GAM). The letter "K" after data value outside the pie means thousands, so that $126.54 \mathrm{~K}$ (rounded up to $127 \mathrm{~K}$ ) is read as one hundred and twenty-seven thousand. Calculation made using census population 2017 and pooled dataset of nutrition surveys collected between 2017 and 2019

in Mozambique

context specific. As for age and sex, it is still uncertain if the observed differences are due to the effect of direct influence of body composition or not, however, based on our findings we suggest assessing whether adding age and sex adjustments to MUAC improves performance. A similar recommendation has also been suggested by Laillou et al., (2014) using data from Cambodia and data from Ethiopia [30].

Lastly, our study shows that the observed discrepancy between WHZ and MUAC has programmatic implications for the treatment of acute malnutrition. In Mozambique many surveys estimate prevalence of acute malnutrition using WHZ and oedema only, despite collecting MUAC data. This means that programmes are planned and costed based on estimates derived from WHZ and oedema only. As shown in our results, using only WHZ and/oedema prevalence estimates accounts for $43.3 \%$ less than the actual number of children in need; using only MUAC and/oedema prevalence accounts for $32.1 \%$ less than the actual number of children in need (Fig. 6). For SAM, WHZ and/oedema-only represented $74.7 \%$ less children and SAM by MUAC and/ oedema-only represented $8.4 \%$ less (Fig. 7) than the actual number of children in need. This means that using either GAM and SAM by WHZ and/oedema-only or GAM and SAM by MUAC and/oedema-only underestimates the number of children in need of treatment leading to unrealistic planning and costing figures affecting the entire value chain of the nutrition programme. This includes advocacy, forecast of nutrition supplies, staffing needs, fundraising and others, both for emergency and non-emergency programmes. This clearly shows that neither diagnostic criteria should be considered alone. Rather, a combination, including bilateral oedema, should be used through the combined prevalence estimates, to ensure accurate programme planning. Our results are consistent with findings reported by Humphreys et al. (2019) [31] in the context of Afghanistan where the Ministry of Public Health acknowledged the differences and adopted the use of the combined prevalence estimates towards more accurate programming [32]. Similarly, consistent with findings reported by Guesdon et., al (2020) [33], our study shows that use of one diagnostic criteria for admission to treatment programmes will 
- Caseload SAMbyWHZ and/or edema - Caseload SAMbyMUAC and/or edema - Caseload cSAM

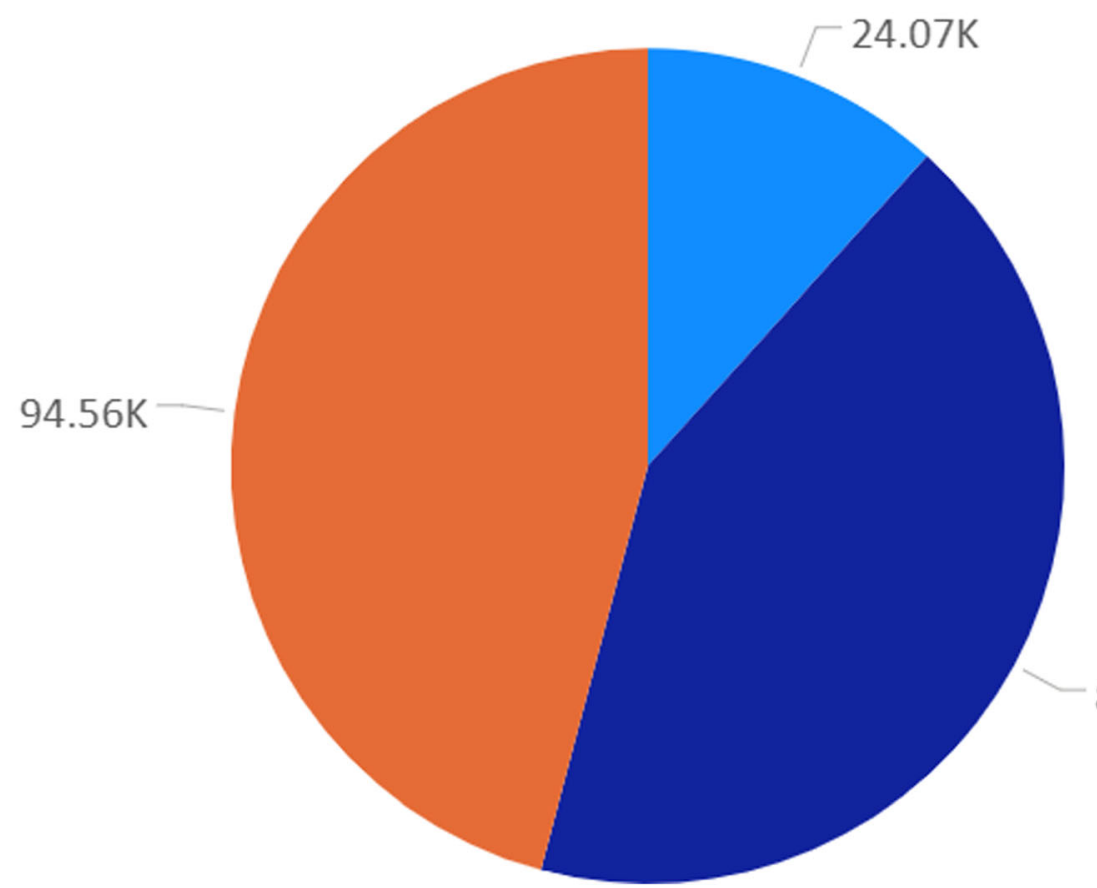

$87.49 \mathrm{~K}$

Fig. 7 Total number of children (in thousands) in need of treatment using SAM by WHZ and/or oedema, SAM by MUAC and/or oedema and CSAM. The letter "K" after data value outside the pie means thousands, so that $24.07 \mathrm{~K}$ (rounded down to $24 \mathrm{~K}$ ) is read as twenty-four thousand. Calculation made using census population 2017 and pooled dataset of nutrition surveys collected between 2017 and 2019 in Mozambique

exclude children in need of treatment (Fig. 2); we suggest that more analysis is necessary to determine the most effective way to identify children in need of treatment.

Mozambique has not yet adopted the use of combined prevalence estimates when calculating the number of children in need of treatment. Our analysis suggests therefore that the planning currently used is sub-optimal given that children in need are excluded by using either one method or the other. We therefore urge the Ministry of Health, Nutrition Cluster and other stakeholders to endorse the use of cGAM (CSAM and cMAM), first by promoting reporting of cGAM in population-based anthropometrics surveys and also when estimating number of children in need of treatment, both in emergency and non-emergency programmes, in order to more accurately reflect the number in need for advocacy, fundraising, procurement of nutrition supplies and other planning considerations. We suggest that further analysis is needed to analyse policy and programmatic implications for Mozambique, including the additional burden that needs to be reached, where that burden is located, if services are available and how services should be targeted. Further, since MUAC is the most simple and practical method to screen children at community level [34] further analysis should be carried out to assess if the power of
MUAC can be increased to capture children that are diagnosed with wasting by WHZ (but not MUAC). This analysis should include severe (as well as global) wasting with adjustments for age and sex considered.

Despite using data from Mozambique only, given the fact that WHZ and MUAC diagnose different children as wasted, as previously documented in many countries including in Africa and Asia (Bilukha \& Leidman, 2018 [32]; Grellety \& Golden, 2016; Laillou et al., 2014; Wieringa et al., 2018 and others), we are confident that our findings are applicable to other settings, however the direction and extent of discordance would need to be contextualized. In other words, our findings around the programmatic implications caused by widely different caseload estimates between WHZ and/oedema only, MUAC and/oedema only and the combined prevalence estimates is also likely to be found in other countries and should be investigated further by country to ensure accurate advocacy and comprehensive response planning.

\section{Limitations}

Some limitations of our study are described as follows: since we used secondary surveys conducted between 2017 and 2019, prevalence estimates presented in our study do not reflect the current situation in the 
respective areas. Also, even though our data came from 9 provinces (of 11) and all the three regions are represented in the sample, the study is not nationally representative as it covers only $28 \%$ of the 161 districts of Mozambique. The fact that we used SMART flags, which consider only children whose measurements are statistically plausible, means that some children with biologically plausible measurements may have been excluded from the study. In our regression models, besides age, sex and stunting, the database used did not have other factors of importance to model behaviour in relation to WHZ and MUAC diagnosis.

\section{Conclusions}

In Mozambique, WHZ and MUAC rarely agree in their diagnostic classification of wasting in the same child, although positive and fair correlation between them exists. Age, sex and stunting all play a significant role on the influence of a wasting diagnosis classification using MUAC. Our study urges stakeholders to officially adopt the use of the combined prevalence estimates of acute malnutrition when calculating the number of children in need, both in routine and emergency programmes and this should be done by first promoting the inclusion of weight, height as well as MUAC and oedema measurements in all population based surveys that include anthropometry for children aged between 6 and 59 months. Additional analysis is recommended to assess the programmatic implications for Mozambique (such as targeting, financial, staffing and supply implications). Further analysis is also needed to ascertain the optimal level of MUAC to diagnose wasting at community or health facility level considering the discrepancies shown in this study.

\section{Abbreviations}

MUAC: Mid upper arm circumference; WHZ: Weight-for-height Z-score; GAM: Global acute malnutrition; CGAM: Combined prevalence of global acute malnutrition; SAM: Severe acute malnutrition; CSAM: Combined prevalence of severe acute malnutrition; CMAM: Combined prevalence of moderate acute malnutrition; SETSAN: Technical secretariat for food security and nutrition; ENA: Emergency nutrition assessment software;

AOR: Associated odds ratio; mm: Millimetres

\section{Acknowledgments}

The authors are thankful to SETSAN for their datasets.

\section{Disclaimer}

The findings and conclusions in this report are those of the authors and do not necessarily represent the official position of the United Nations Children's Fund.

\section{Authors' contributions}

TZ conceptualized the research project. TZ performed data curation, analysis, interpreted analysis results and wrote first draft of the manuscript. MN and $J L A$ reviewed and edited the manuscript. Critical revision of the manuscript for important intellectual content: All Authors. The author (s) read and approved the final manuscript.

\section{Authors' information}

Not applicable.

Funding

None.

\section{Availability of data and materials}

The datasets used and/or analysed during the current study are available from the corresponding author on reasonable request.

\section{Ethics approval and consent to participate}

Authors used secondary data belonging to SETSAN and UNICEF, hence no licence was required for its utilization.

\section{Consent for publication}

Not applicable.

\section{Competing interests}

None.

\section{Author details}

${ }^{1}$ United Nations Children's Fund, 1440 Zimbabwe Avenue, Maputo, Mozambique. ${ }^{2}$ United Nations Children's Fund, Eastern and Southern Africa Regional Office, Box 44145-00100, Nairobi, PO, Kenya. Independent Consultant, 2 Artichoke Hill, London, UK.

Received: 23 June 2020 Accepted: 26 August 2020

Published online: 07 October 2020

\section{References}

1. Cooten MH, Bilal SM, Gebremedhin S, Spigt M. The association between acute malnutrition and water, sanitation, and hygiene among children aged 6-59 months in rural Ethiopia. Matern Child Nutr. 2019;15(1):1-8 Available from: https://onlinelibrary.wiley.com/doi/abs/10.1111/mcn.12631.

2. Development Initiatives. 2020 Global Nutrition Report: Action on equity to end malnutrition. Bristol; 2020. Available from: https://globalnutritionreport. org/reports/2020-global-nutrition-report/.

3. Frison S, Kerac M, Checchi F, Nicholas J. A novel, efficient method for estimating the prevalence of acute malnutrition in resource-constrained and crisis-affected settings: A simulation study. PLoS One. 2017;12(11):1-13.

4. WHO and UNICEF. Child growth standards and the identification of severe malnutrition. Geneva: WHO and UNICEF; 2009. Available from: http://www. who.int/nutrition/publications/severemalnutrition/9789241598163_eng.pdf.

5. IPC TWG. Relatório da Avaliação da Situação de Segurança Alimentar e Nutricional: Maputo; 2017.

6. IPC TWG. Resultados das análises de IPC conduzidas em 10 distritos no período de Março a Abril de 2018 e Projectado para o período Setembro de 2018 a Fevereiro de 2019: Maputo; 2018. Available from: http://www. ipcinfo.org/ipc-country-analysis/details-map/en/c/1151780/?iso3=MOZ.

7. Laillou A, Prak S, de Groot R, Whitney S, Conkle J, Horton L, et al. Optimal Screening of Children with Acute Malnutrition Requires a Change in Current WHO Guidelines as MUAC and WHZ Identify Different Patient Groups. PLoS One. 2014;9(7):e101159 Available from: https://dx.plos.org/10.1371/journal. pone.0101159. Bhutta ZA, editor.

8. Tadesse A, Tadesse E, Berhane Y, Ekström E-C. Comparison of Mid-Upper Arm Circumference and Weight-for-Height to Diagnose Severe Acute Malnutrition: A Study in Southern Ethiopia. Nutrients. 2017;9(3):1-12 Available from: http://www.mdpi.com/2072-6643/9/3/267.

9. Ministério da Saúde (MISAU), Instituto Nacional de Estatística (INE), ICF Internation (ICFI). Moçambique Inquérito Demográfico e de Saúde 2011. Calverton, Maryland; 2011. p. 1-430.

10. Wieringa F, Gauthier L, Greffeuille V, Som S, Dijkhuizen M, Laillou A, et al. Identification of Acute Malnutrition in Children in Cambodia Requires Both Mid Upper Arm Circumference and Weight-For-Height to Offset Gender Bias of Each Indicator. Nutrients. 2018;10(6):786 Available from: www.mdpi. com/journal/nutrients.

11. Bilukha O, Leidman E. Concordance between the estimates of wasting measured by weight-for-height and by mid-upper arm circumference for classification of severity of nutrition crisis : analysis of populationrepresentative surveys from humanitarian settings. BMC Nutr. 2018:4(24):110 https://doi.org/10.1186/s40795-018-0232-0. 
12. Grellety E, Golden MH. Weight-for-height and mid-upper-arm circumference should be used independently to diagnose acute malnutrition: policy implications. BMC Nutr. 2016;2(1):10 Available from: http://www. biomedcentral.com/2055-0928/2/10/.

13. MISAU. Manual de Tratamento e Reabilitação Nutricional Volume I. 2011th ed. Vol. I, Ministério da Saúde de Moçambique. Maputo: Ministerio de Saude; 2011. p. 1-173.

14. MISAU. Manual de Tratamento e Reabilitação Nutricional Volume I: 0 aos 14 Anos. $2^{a}$ edicão. 2nd ed: República de Moçambique: Ministério da Saúde, Departamento de Nutrição; 2018. p. 207. Available from: https://www. fantaproject.org/sites/default/files/resources/PRN-I-Manual-TratamentoReabilitação-Nutricional-Vol-I-Set2018.pdf.

15. WHO. Guideline: Updates on the management of severe acute malnutrition in infants and children. Geneva: World Health Organization; 2013. p. 123. Available from: https://www.who.int/nutrition/publications/guidelines/ updates_management_SAM_infantandchildren/en/.

16. Myatt M, Khara T, Collins S. A review of methods to detect cases of severely malnourished children in the community for their admission into community-based therapeutic care programs. Food Nutr Bull. 2006; 27(SUPPL.3) Available from: https://journals.sagepub.com/doi/10.1177/1564 82650602735302.

17. IPC Global Partners. Integrated Food Security Phase Classification Technical Manual Version 3.0. Evidence and Standards for Better Food Security and Nutrition Decisions. Rome; 2019. p. 1-210. Available from: http://www. ipcinfo.org/fileadmin/user_upload/ipcinfo/manual/IPC_Technical_Manual_3_ Final.pdf.

18. SMART. Standardized Monitoring and Assessment of Relief and Transitions. 2Ed ed. Canada: SMART Methodology; 2017. p. 1-146. Available from: https://smartmethodology.org/wp-content/uploads/2018/02/SMARTManual-2.0_Final_January-9th-2017-for-merge-3.pdf.

19. Kestenbaum B. In: Weiss NS, Shoben A, editors. Epidemiology and Biostatistics: An Introduction to Clinical Research. 2nd Edi ed. Cham: Springer International Publishing; 2019. p. 1-192. Available from: http://link. springer.com/10.1007/978-3-319-96644-1.

20. Gisev N, Hons BP, Bell JS, Ph D, Chen TF, Ph D. Interrater agreement and interrater reliability : Key concepts, approaches, and applications. Res Soc Adm Pharm. 2013;9(3):330-8. https://doi.org/10.1016/j.sapharm.2012.04.004.

21. McHugh ML. Interrater reliability: the kappa statistic. Biochem Medica. 2012; 22(3):276-82 Available from: https://www.ncbi.nlm.nih.gov/pmc/articles/ PMC3900052/.

22. Mukaka MM. Statistics corner: A guide to appropriate use of correlation coefficient in medical research. Malawi Med J. 2012;24(3):69-71.

23. De WJCF, Gosling SD, Potter J. Comparing the Pearson and Spearman Correlation Coefficients Across Distributions and Sample Sizes : A Tutorial Using Simulations and Empirical Data. Psychol Methods. 2016;21(3):273-90.

24. Bursac Z, Gauss CH, Williams DK, Hosmer DW. Purposeful selection of variables in logistic regression. Source Code Biol Med. 2008;3(1):17 Available from: https://scfbm.biomedcentral.com/articles/10.1186/1751-0473-3-17.

25. Sperandei S. Understanding logistic regression analysis. Biochem Medica. 2014;24(1):12-8 Available from: http://www.biochemia-medica.com/en/ journal/24/1/10.11613/BM.2014.003.

26. Isanaka S, Grais RF, Briend A, Checchi F. Estimates of the Duration of Untreated Acute Malnutrition in Children From Niger. Am J Epidemiol. 2011 173(8):932-40 Available from: https://academic.oup.com/aje/article-lookup/ doi/10.1093/aje/kwq436.

27. Weber DR, Leonard MB, Zemel BS. Body composition analysis in the pediatric population. Pediatr Endocrinol Rev. 2012;10(1):130-9 Available from: http://www.ncbi.n/m.nih.gov/pubmed/23469390.

28. Briend A, Khara T, Dolan C. Wasting and stunting--similarities and differences: policy and programmatic implications. Food Nutr Bull. 2015;36(1 Suppl):S15-23 Available from: http://www.ncbi.nlm.nih.gov/pubmed/25 902610

29. Garenne M, Myatt M, Khara T, Dolan C, Briend A. Concurrent wasting and stunting among under-five children in Niakhar, Senegal. Matern Child Nutr. 2019;15(2):e12736 Available from: https://onlinelibrary.wiley.com/doi/abs/1 $0.1111 / \mathrm{mcn} .12736$

30. Myatt M, Duffield A, Seal A, Pasteur F. The effect of body shape on weightfor-height and mid-upper arm circumference based case definitions of acute malnutrition in Ethiopian children. Ann Hum Biol. 2009;36(1):5-20 Available from: http://www.tandfonline.com/doi/full/10.1080/030144608024 71205.
31. Tessema M, Laillou A, Tefera A, Teklu Y, Berger J, Wieringa FT. Routinely MUAC screening for severe acute malnutrition should consider the gender and age group bias in the Ethiopian non-emergency context. PLoS One. 2020;15(4):1-11. https://doi.org/10.1371/journal.pone.0230502 Gebremedhin S, editor.

32. Humphreys A, Sarker B, Habib BB, Dobamo AG. Estimating ' people in need ' from combined GAM in Afghanistan. ENN Field Exchange. 2019;(61):11 Available from: www.ennonline.net/fex/61/gamafghanistan.

33. Guesdon B, Couture A, Pantchova D, Bilukha O. Potential consequences of expanded MUAC-only programs on targeting of acutely malnourished children and ready-to-use-therapeutic-food allocation: lessons from crosssectional surveys. BMC Nutr. 2020;6(1):5 Available from: https://bmcnutr. biomedcentral.com/articles/10.1186/s40795-019-0328-1.

34. Roberfroid D, Hammami N, Lachat C, Prinzo ZW, Sibson V, Guesdon B, et al. Utilization of mid-upper arm circumference versus weight-for-height in nutritional rehabilitation programmes: a systematic review of evidence. World Heal Organ. 2013:1-23 Available from: http://www.who.int/entity/ nutrition/publications/guidelines/updates_management_SAM_ infantandchildren_review1.pdf.

\section{Publisher's Note}

Springer Nature remains neutral with regard to jurisdictional claims in published maps and institutional affiliations.
Ready to submit your research? Choose BMC and benefit from:

- fast, convenient online submission

- thorough peer review by experienced researchers in your field

- rapid publication on acceptance

- support for research data, including large and complex data types

- gold Open Access which fosters wider collaboration and increased citations

- maximum visibility for your research: over $100 \mathrm{M}$ website views per year

At BMC, research is always in progress.

Learn more biomedcentral.com/submissions 